\title{
Formulation development and investigation of domperidone transdermal patches
}

\author{
Prabhakar Prabhu, Samip Shah, Shankar Gundad \\ Department of Pharmaceutics, N.G.S.M. Institute of Pharmaceutical Sciences, Mangalore, India
}

\begin{abstract}
Aim and Background: Domperidone is a dopamine antagonist with antiemetic properties having a plasma half life of 7-9 $\mathrm{h}$ with $15 \%$ oral bioavailability. In the present work transdermal patches of domperidone were prepared with the objective to improve its therapeutic efficacy, patient compliance and to reduce the frequency of dosing and side effects, as well as to avoid its extensive first pass metabolism of the drug. Materials and Methods: The patches were prepared using ethyl cellulose (EC): Poly vinyl pyrrolidone (PVP), poly vinyl alcohol (PVA): Poly vinyl pyrrolidone (PVP) and hydroxypropylmethylcellulose (HPMC): Sodium (carboxy methyl cellulose) CMC as polymers in combination. The physicochemical parameters like thickness, drug content, weight variation, moisture absorption and drug permeation studies were evaluated for the prepared patches. No significant difference in thickness, average weight and in the drug content among the patches. Results: It was observed that from hydrophilic polymers the drug release was found to be faster compared to (F5 and F6 \& F3 and F4) combination of hydrophilic and lipophilic polymers used in the study. Patches containing HPMC and Sodium CMC (F5 and F6) showed faster release as the patches showed maximum percentage amount moisture absorption. The in vitro release data was treated with kinetic equations and it followed Higuchi's diffusion mechanism. The in vivo bioavailability study was performed in rats and observed that, drug reached to the peak in approximately 60 min (16\%) after oral route of administration. However, approximately same amount of drug was found in the serum from transdermal formulation in $6 \mathrm{~h}$ and further increase in the amount of drug in the serum, indicated that the drug 5 bioavailability could be better and hence the hepatic metabolism can be avoided, as it is evident from the data. Further, the decrease in the amount of drug present in the serum 45 min after oral administration also indicated that major amount of drug might have got metabolized and the bioavailability is reduced. However, the transdermal patch released further amount of drug (33\%) at the end of $24 \mathrm{~h}$. Conclusion: The present study can be concluded that transdermal patch can extend the release of drug for many hours with better bioavailability and also can avoid the first pass effect.
\end{abstract}

Key words: Domperidone, in vitro and in vivo release study, transdermal patch

\section{INTRODUCTION}

Transdermal drug delivery system (TDDS) is topically administered medicamentsin the form of patches that deliver drugs across a patient's skin for systemic effects at a predetermined and controlled rate. Transdermal delivery not only provides controlled, constant administration of the drug, but also allows continuous input of drugs with short biological

\section{Address for correspondence:}

Mr. Samip S Shah,

N.G.S.M. Institute of Pharmaceutical Sciences, Mangalore,

Karnataka, India. E-mail: samipshah2008@yahoo.com

\begin{tabular}{|l|l|}
\hline \multicolumn{2}{|c|}{ Access this article online } \\
\hline Quick Response Code: & Website: \\
\hline & www.jpionline.org \\
\cline { 2 - 2 } & DOI: \\
\hline
\end{tabular}

half-lives and eliminates pulsed entry into systemic circulation, which often causes undesirable side effects. ${ }^{[1]}$

Among the wide variety of novel drug delivery systems, the transdermal delivery of drugs for the systemic treatment of diseases has acquired increasing interest in recent years due to its potential in avoiding the hepatic first pass effect, thus achieving high systemic bioavailability of drugs, which undergo either considerable or extensive first-pass metabolism and they are capable of sustaining the drug release for prolonged period of time. Moreover, it provides suitability for self-administration and rapid termination of drug effect if needed, leading to better patient acceptance and compliance. ${ }^{[2]}$

Domperidone is a dopamine antagonist with antiemetic properties. Its antiemetic effect is due to a combination of peripheral (gastro kinetic) effect and antagonism of central dopamine receptors in the chemo-receptor trigger zone, which lies in the area postrema. It is rapidly absorbed following oral administration and peak plasma concentration is reached within 30-60 min. The solubility of domperidone is related to $\mathrm{pH}$, and is showing poor solubility in 
intestinal $\mathrm{pH}$. Plasma half- life of domperidone is $7-9 \mathrm{~h}$ with $15 \%$ oral bioavailability. In the treatment of nausea and vomiting in parkinsonian patients, domperidone therapy may be continued for a maximum of 12 weeks, which requires the necessity of sustained formulation. Hence, to improve its therapeutic efficacy, patient compliance and to reduce the frequency of dosing and side effects, as well as to avoid its extensive first pass metabolism, transdermal drug delivery approach was considered to be better suitable for domperidone. ${ }^{[3,4]}$

In view of the above facts, in the present investigation, an attempt is made to develop matrix type transdermal patches of domperidone using suitable polymers like polyvinyl alcohol, polyvinylpyrrolidone, HPMC, sodium CMC, ethyl cellulose.

\section{MATERIALS AND METHODS}

\section{Materials}

Domperidone was obtained as a gift sample from Torrent Pharmaceutical, Ahmedabad. Poly vinyl alcohol (cold) was procured from $\mathrm{CDH}$ Laboratory reagent, Mumbai; Poly vinyl pyrolidone K-30 from Ozone International, Mumbai; Ethyl cellulose from Sulab Reagent, Baroda; Sodium Carboxymethyl cellulose from Loba Chemical Pvt. Ltd., Mumbai; Hydroxy propyl methylcellulose from Reachem Laboratory Chemicals Pvt. Ltd., New Delhi. All other chemicals and reagents used were of analytical reagent grade.

\section{Formulation of transdermal patches}

In the present study, matrix type transdermal patches of domperidone were prepared by molding technique. A flat square shaped, aluminum foil coated glass molds having surface area of $25 \mathrm{~cm}^{2}$ were fabricated for casting the patches.

\section{Preparation of casting solutions}

For Ethyl cellulose and PVP (F1 and F2)

The casting solutions were prepared by dissolving weighed quantities [Table 1] of polymers in chloroform. The drug is dissolved in DMF and added to the above polymer solution along with Di-butylphathalate, as plasticizer, thoroughly mixed to form a homogeneous mixture. The volume was made up to $10 \mathrm{ml}$ with chloroform. Entrapped air bubbles were removed by applying vacuum.

\section{For PVA and PVP Polymers (F3 and F4)}

The casting solutions were prepared by dissolving weighed quantities [Table 2] of polymers in water by heating on water bath. The drug is dissolved in DMF and added to the above polymer solution along with Di-butylphathalate, as plasticizer, thoroughly mixed to form a homogeneous mixture. The volume was made up to $10 \mathrm{ml}$ with water. Entrapped air bubbles were removed by applying vacuum.

\section{For HPMC and Sodium CMC (F5 and F6)}

The castings solutions were prepared in similar way as described for PVA: PVP solution by using HPMC and sodium CMC polymers [Table 3]..$^{[5,6]}$

\section{Preparation of transdermal patches}

Ten milliliter of the casting solution was poured into glass moulds and dried in hot air if necessary after 24 hours of controlled evaporation at room temperature for 24 hours for solvent evaporation. The patches were removed by peeling and cut into square dimension of $3 \mathrm{~cm} \times 3 \mathrm{~cm}\left(9 \mathrm{~cm}^{2}\right)$. These patches were kept in desiccator for 2 days for further drying and wrapped in aluminum foil, packed in self-sealing covers.

\begin{tabular}{lccccccc}
\multicolumn{2}{l}{ Table 1: Formulation of $\mathrm{EC}$ and PVP combination } \\
\hline Code & $\begin{array}{c}\text { Polymer ratio } \\
\text { EC/PVP }\end{array}$ & $\begin{array}{c}\text { Ethyl cellulose } \\
\text { (mg) }\end{array}$ & $\begin{array}{c}\text { Polyvinyl } \\
\text { pyrrolidone }(\mathbf{m g})\end{array}$ & $\begin{array}{c}\text { Domperidone } \\
\text { (mg) }\end{array}$ & $\begin{array}{c}\text { Di-butyl } \\
\text { phathalate (ml) }\end{array}$ & DMF & Water \\
\hline F1 & $9: 1$ & 900 & 100 & 250 & 0.1 & 0.5 & 10 \\
F2 & $8: 2$ & 800 & 200 & 250 & 0.1 & 0.5 & 10 \\
\hline
\end{tabular}

EC: Ethyl cellulose, PVP: Poly vinyl pyrrolidone

\begin{tabular}{lccccccc} 
Table 2: & Formulation of PVA and PVP & combination & & \\
\hline Code & $\begin{array}{c}\text { Polymer ratio } \\
\text { PVA/PVP }\end{array}$ & $\begin{array}{c}\text { Poly vinyl } \\
\text { alcohol }(\mathbf{m g})\end{array}$ & $\begin{array}{c}\text { Polyvinyl } \\
\text { pyrrolidone }(\mathbf{m g})\end{array}$ & $\begin{array}{c}\text { Domperidone } \\
\text { (mg) }\end{array}$ & $\begin{array}{c}\text { Di-butyl } \\
\text { phathalate (ml) }\end{array}$ & DMF & Water \\
\hline F3 & $1: 1$ & 250 & 250 & 222 & 250 & 1 & 0.5 \\
F4 & $1.25: 1$ & 278 & 250 & 1 & 10 & 0.5 & 10 \\
\hline
\end{tabular}

PVP: Poly vinyl pyrrolidone

\begin{tabular}{lccccccc} 
Table 3: Formulation of HPMC and sodium CMC combination & & \\
\hline Code & $\begin{array}{c}\text { Polymer ratio } \\
\text { HPMC/Sodium CMC }\end{array}$ & HPMC (mg) & $\begin{array}{c}\text { Sodium CMC } \\
\text { (mg) }\end{array}$ & $\begin{array}{c}\text { Domperidone } \\
\text { (mg) }\end{array}$ & $\begin{array}{c}\text { Di-butyl } \\
\text { phathalate (ml) }\end{array}$ & $\begin{array}{c}\text { DMF } \\
\text { Water }\end{array}$ \\
\hline F5 & $1: 1$ & 250 & 250 & 250 & 1 & 0.5 & 10 \\
F6 & $1.25: 1$ & 278 & 222 & 250 & 1 & 0.5 & 10 \\
\hline
\end{tabular}

HPMC: Hydroxyl propyl methyl cellulose, CMC: Sodium carboxy methyl cellulose 


\section{Evaluation of transdermal patches}

Physicochemical parameters

\section{Physical appearance}

All the transdermal patches were visually inspected for color, flexibility, homogenecity, and smoothness.

\section{Film thickness}

The thickness of the patches was measured at five different places on a single patch of each formulation using a screw gauge and the mean values were calculated. ${ }^{[6]}$

\section{Weight variation}

A set of three patches from each batch having a diameter of 1 $\mathrm{cm}^{2}$ were weighed on a digital balance and the mean values were calculated. The tests were performed on films which were dried at $60^{\circ} \mathrm{C}$ for $4 \mathrm{~h}$ prior to testing. ${ }^{[7]}$

\section{Drug content uniformity}

The patch $\left(1 \mathrm{~cm}^{2}\right)$ was transferred into a graduated glass stopper flask containing $100 \mathrm{ml}$ of phosphate buffer 6.8. The flask was shaken for $4 \mathrm{~h}$ in a mechanical shaker. Then the solution was filtered and $1 \mathrm{ml}$ diluted to $10 \mathrm{ml}$ with of phosphate buffer and the absorbance was measured at $283 \mathrm{~nm}$ using the placebo patch solution as blank and the drug content was calculated. ${ }^{[8]}$

\section{Folding endurance}

A strip of $2 \mathrm{~cm} \times 2 \mathrm{~cm}\left(4 \mathrm{~cm}^{2}\right)$ was subjected to folding endurance by folding the patch at the same place repeatedly several times until a visible crack was observed and the values were reported. ${ }^{[9]}$

\section{Elongation and tensile strength}

These mechanical properties were evaluated using Instron universal testing instrument (model F. 4026), Instron Ltd, Japan, NITK, surathkal) with a $5 \mathrm{~kg}$ load cell. Film strips in special dimension and free from air bubbles or physical imperfections were held between two clamps positioned at a distance of 3 $\mathrm{cm}$. During measurement, the strips were pulled by the top clamps at a rate of $100 \mathrm{~mm} / \mathrm{min}$; the force and elongation were measured when the film broke. Results from film samples, which broke at and not between the clamps, were not included in the calculations. Measurements were run in triplicate for each film. Two mechanical properties, namely tensile strength and percentage elongation, were computed for the evaluation of the film. Tensile strength is computed from the following equation ${ }^{[10]}$

\section{Break force}

$\begin{array}{cc}\text { Tensile strength }= & \begin{array}{c}\text { Initial cross sectional are } \\ \text { of the sample }\left(\mathrm{mm}^{2}\right)\end{array}\end{array}$

Percentage elongation can be obtained by following equation:

$$
\% \text { Elongation at break }=\frac{\text { Increase in length } \times 100}{\text { Original length }}
$$

\section{Hardness}

To determine the hardness of the patches, an apparatus was designed in our laboratory to study the hardness of the films using the literature report. It consists of a wooden stand of 11 $\mathrm{cm}$ height and top area of $16 \mathrm{~cm} \times 16 \mathrm{~cm}$. A small pan was fixed horizontally to one end of the $2 \mathrm{~mm}$ thick iron rod whose other end is reduced to a sharp point. A hole of $0.2 \mathrm{~cm}$ was made at the center of tip area of wooden stand, which was supported on the pan rod. An electric circuit was developed through a 3 volt battery in such a way that the bulb glows only when the circuit is completed through the contact of a metal plate and sharp end of the rod. The film was placed between the metal plate and sharp end of the rod. The weights were gradually added at an interval of 10 seconds for the stabilization of the force till the bulb was glow. The final weight was considered as a measure of hardness. ${ }^{[1]}$

\section{Moisture absorption}

Films $\left(1 \mathrm{~cm}^{2}\right)$ of each formulation were accurately weighed and exposed to atmospheric conditions of temperature (average temp $34^{\circ} \mathrm{C}$ ) and humidity (75\%) for three days. After three days, the films were again weighed and $\%$ moisture absorption was calculated. Average $\%$ moisture absorption of each film was calculated. ${ }^{[12]}$

$\%$ Moisture absorption $=($ Final weight - Initial weight $) \times 100$

Initial weight

\section{In vitro drug release studies}

In vitro drug release profiles were carried out by using modified Keshery - Chein diffusion cell with cellophane membrane. The cell consists of two compartments, the donor and the receptor compartment. The donor compartment was in contact with ambient conditions of the atmosphere. The receptor compartment was in contact with a solution in the receptor compartment (phosphate buffer $\mathrm{pH}$ 6.8) and the contents were stirred by a rod-shaped magnetic bead driven by a magnetic stirrer. One patch of $1 \mathrm{~cm}^{2}$ was placed in the donor compartment of the diffusion cell. The receptor fluid $(5 \mathrm{ml})$ was withdrawn at predetermined time intervals and replaced immediately with same volume of phosphate buffer $\mathrm{pH}$ 6.8. The samples were analyzed for drug content at $283 \mathrm{~nm}$ using UV-visible spectrophotometer (Shimadzu, Japan) after suitable dilution with phosphate buffer $\mathrm{pH} 6.8 .^{[12]}$

\section{In vivo drug release studies}

The in vivo experimental protocol described in this study was approved by the Institutional Animal Ethical Committee (KSHEMA/AEC/066) and was in accordance with the guidelines of the Committee for Purpose of Control and Supervision of Experiments on Animals, Ministry of Social Justice and Empowerment, Government of India. All efforts were made to minimize animal suffering and to limit the number of animal used. ${ }^{[13]}$ In this study, six rabbits weighing $1.5 \mathrm{~kg}$ were selected for each group (control and drug). After cleaning the dorsal surface, hair was removed. The dose of domperidone was calculated according to the body weight. Transdermal patch of $4.1 \mathrm{~cm}^{2}$ was placed on the dorsal surface of the rabbit and immediately secured with an adhesive tape. Blood samples $(0.5 \mathrm{ml})$ were withdrawn 
from the marginal ear vein into heparinized glass vessels at predetermined time intervals for the estimation drug in plasma. The blood samples were immediately centrifuged at $2000 \mathrm{rpm}$ for $10 \mathrm{~min}$ and plasma was separated and extracted with ethyl acetate followed by final preparation of sample with mobile phase (mixture of buffer: acetonitrile: methanol (55:35:10) at $1 \mathrm{~mL} / \mathrm{min}$ flow rate) analyzed for drug content by HPLC (instrumentation comprises of A Shimadzu's HPLC (LC-2010-HT, Shimadzu, Singapore) equipped with UV-Visible Detector, phenomenex, C18, ODS column $(250 \mathrm{~mm}$ X $4.6 \mathrm{~mm} ; 5 \mu$.), Hamilton $20 \mu \mathrm{L}){ }^{[14]}$

\section{Compatibility studies}

In the present study, compatibility studies were carried out to assess any incompatibility between the drug and polymers. The IR studies were performed to check the compatibility of excipients. Spectra of the pure drug, PVA, PVP, sodium CMC, HPMC, ethyl cellulose and the formulated patch were taken individually by the potassium bromide pellet method. ${ }^{[15]}$

\section{Stability studies}

The short term stability studies of the formulated transdermal patches were carried out on prepared films at different temperature and humidity according to ICH guidelines: $25 \pm$ $2^{\circ} \mathrm{C}(60 \% \mathrm{RH})$ and $45 \pm 2{ }^{\circ} \mathrm{C}(75 \% \mathrm{RH})$ a period of 60 days. The patches were wrapped in aluminum foil and stored in desiccator for stability study. The patches were characterized for drug content and other parameters at regular intervals. ${ }^{[15,16]}$

\section{Skin irritancy studies}

Patches were applied to the shaved skin on one side of the back of rabbit and secured using adhesive tape. On other back side of the rabbit, control patch (without drug) was secured in a similar way. The animal was observed for any sign of erythema or edema for a period of $48 \mathrm{~h}$.

\section{Lamination of transdermal patch}

The transdermal patch of $3 \mathrm{~cm}$ diameter was cut and placed on an aluminum foil of $3.5 \mathrm{~cm}$ diameter that serves as the backing membrane. A solution of polyisobutylene was applied along the circumference of the aluminum foil and dried at room temperature for $10 \mathrm{~h}$. The patch was covered with silicone-coated release liner. ${ }^{[16]}$

\section{RESULT AND DISCUSSION}

All the patches prepared with different polymer concentration were found to be flexible, smooth, opaque, non-sticky, and homogeneous in nature. Thickness and average weight of the patches did not show any significant difference. All the six formulations have showed good folding endurance indicated that the patches have good flexibility [Table 4].

Water absorption studies revealed that as the concentration of PVP and HPMC increased, the amount of water absorption also increased. Among the patches, F6 patch (HPMC: Sod. CMC 1.25: 1) showed higher moisture absorption. This may be due to the hydrophilic nature of the sod. CMC. The least percentage of moisture absorption was observed for F3 patch (PVA: PVP 1: 1) as compared to F6. The concentration of polymer exhibited significant effect on the percentage elongation, tensile strength. It was found that as the concentration of PVP increased the percentage elongation and tensile strength was also increased along with hardness. It was also found that the patches containing high concentration of plasticizer $(0.1 \%$ with EC: PVP compared to $0.01 \%$ with HPMC: sod. CMC and PVA: PVP) the percentage of elongation and tensile strength were found to be increased [Table 5]. There was no significant difference in the drug content among the patches indicated content uniformity [Table 6].

In vitro drug release study showed that from hydrophilic polymers the drug release was found to be faster compared to (F5 and F6 \& F3 and F4) combination of hydrophilic and lipophilic polymers used in the study [Figure 1]. Patches prepared with PVP and EC as polymers it was found that more the amount of PVP better the drug release due to the hydrophilic nature of PVP. No significant change in drug release was observed from patches containing PVP and PVA irrespective of the polymer

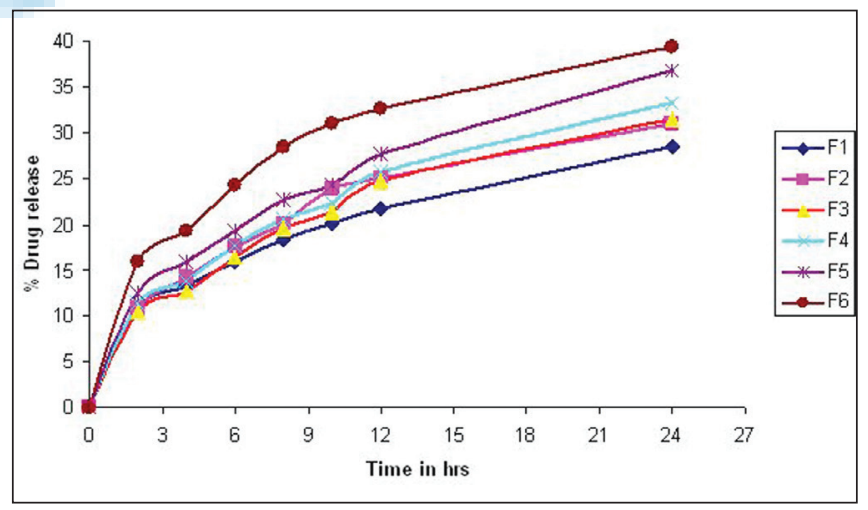

Figure 1: Comparison of in vitro \% drug release of formulations.

Table 4: Physicochemical properties of the prepared transdermal patches

\begin{tabular}{|c|c|c|c|c|c|c|}
\hline Code & Flexibility & Smoothness & Transparency & Stickiness & $\begin{array}{l}{ }^{*} \text { Folding } \\
\text { endurance }\end{array}$ & $\begin{array}{c}{ }^{*} \text { Weight }(\mathrm{mg}) \\
\text { AM } \pm S D\end{array}$ \\
\hline F1 & Flexible & Smooth & Opaque & Non-sticky & $182-215$ & $31.000 \pm 2.000$ \\
\hline F2 & Flexible & Smooth & Opaque & Non-sticky & $182-215$ & $32.333 \pm 2.516$ \\
\hline F3 & Flexible & Smooth & Opaque & Non-sticky & $182-215$ & $31.333 \pm 1.154$ \\
\hline F4 & Flexible & Smooth & Opaque & Non-sticky & $182-215$ & $33.667 \pm 1.154$ \\
\hline F5 & Flexible & Smooth & Opaque & Non-sticky & $199-245$ & $30.667 \pm 1.527$ \\
\hline F6 & Flexible & Smooth & Opaque & Non-sticky & $199-245$ & $31.333 \pm 2.518$ \\
\hline
\end{tabular}




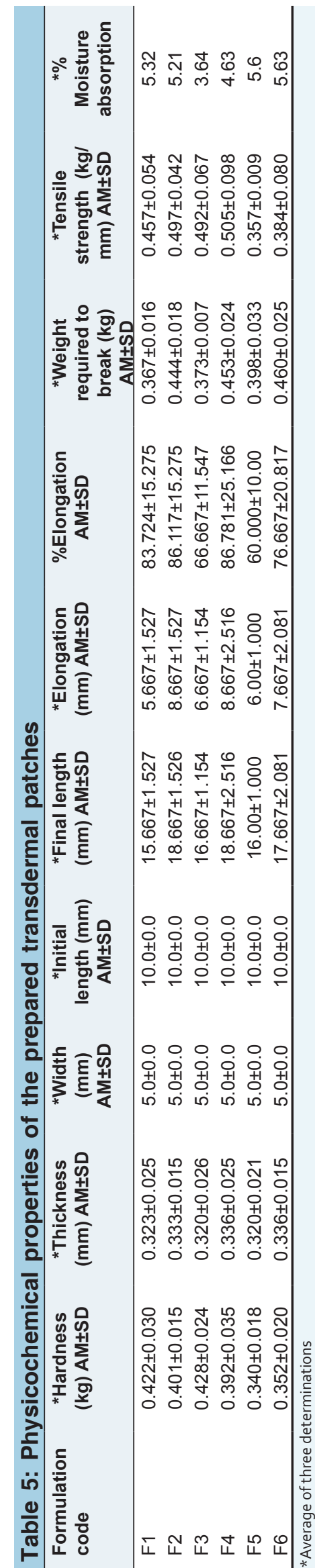

ratio (F3 and F4). Patches containing HPMC: sod. CMC (F5 and F6) showed faster release as the patches showed highest \% of moisture absorption which might have lead to faster release of drug from the patches. This may be attributed to hydrophilic nature of the polymer which has more affinity for water results in increased thermodynamic activity of the drug in the film. Further, the drug release study (F6) was when conducted for $48 \mathrm{~h}$, it was observed that approximately $75 \%$ of drug was released. Hence, transdermal patches can be used for extended period of time.

The in vivo drug release study was performed in rabbits and the data was compared with that of in vitro drug release data. In this study, drug was administered to animal in the form of suspension in water by oral route as well as in the form of transdermal patches same dose was maintained in both formulations. It was observed that the drug reached to the peak in approximately $60 \mathrm{~min}(16 \%)$ from oral route. However, approximately same amount of drug was observed in the serum from transdermal formulation in $6 \mathrm{~h}$ [Figure 2] and further increase in the amount of drug in the serum, indicated that the drug bioavailability could be better and hence the hepatic metabolism can be avoided, as it is evident from the data.

Further, the decrease in the amount of drug present in the serum $45 \mathrm{~min}$ after oral administration also indicates that major amount of drug might have got metabolized and the bioavailability is reduced. However, the transdermal patch released further amount of drug (33\%) at the end of $24 \mathrm{~h}$. Hence, from the present study it can be concluded that transdermal patch can extend the release of drug for many hours with better bioavailability and also can

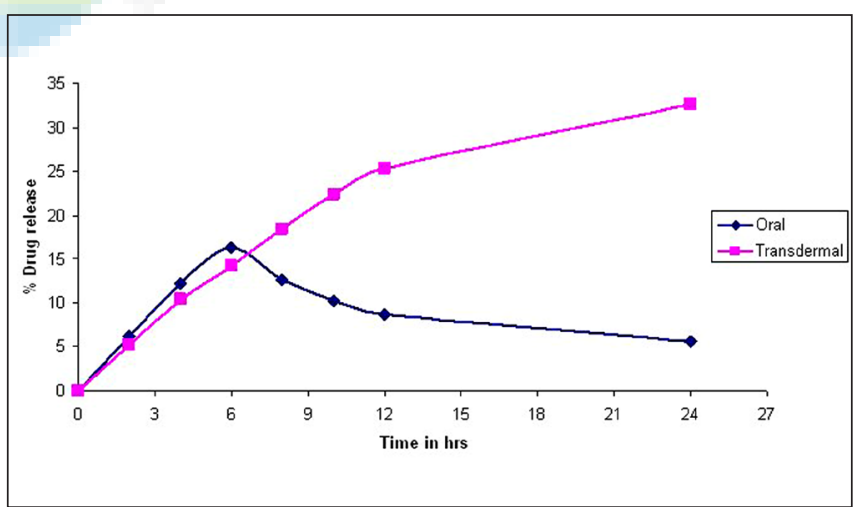

Figure 2: Comparison of oral and transdermal route formulation.

\begin{tabular}{lcc}
$\begin{array}{l}\text { Table 6: Drug content of the prepared } \\
\text { transdermal patches }\end{array}$ \\
$\begin{array}{lcc}\text { Formulation } \\
\text { code }\end{array}$ & $\begin{array}{c}\text { Amount in } \mathbf{1} \mathbf{~ c m}^{2} \\
(\mathbf{m g})\end{array}$ & $\begin{array}{c}\text { Percentage drug } \\
\text { content In } \mathbf{1} \mathbf{~ c m}^{2}\end{array}$ \\
\hline F1 & $9.45 \pm 0.0212$ & $94.50 \pm 0.4124$ \\
F2 & $9.32 \pm 0.0354$ & $93.25 \pm 0.6256$ \\
F3 & $9.15 \pm 0.0241$ & $91.57 \pm 0.5325$ \\
F4 & $9.60 \pm 0.0428$ & $96.06 \pm 0.4546$ \\
F5 & $9.26 \pm 0.0295$ & $92.57 \pm 0.7412$ \\
F6 & $9.80 \pm 0.0374$ & $98.31 \pm 0.5125$ \\
\hline
\end{tabular}

*Average of three determinations 
avoid the first pass effect as the drug undergoes extensive first pass effect approximately $80 \%$.

To understand order of release and release mechanism of the drug from the prepared films, obtained release data was processed into the zero and first order kinetics. The data from in vitro release studies of transdermal patches did not fit into zero order kinetics. Further to know mechanism of release, plotted Higuchi plot, which indicated diffusion as dominating mechanism of drug release [Table 7].
IR studies were done for pure drug, HPMC, sodium CMC, PVA, PVP,EC and formulated films to know the interaction between drug and polymers. From these spectra's it was observed that there was no significant change in the original peak of the drug, polymers when compared with the spectra's of formulated films and this indicates that there is no interaction between drug and polymers [Figure 3].

Stability studies showed that, there is no significant change in physical characteristics and drug content [Table 8]. Based on these results it was concluded that the formulated transdermal

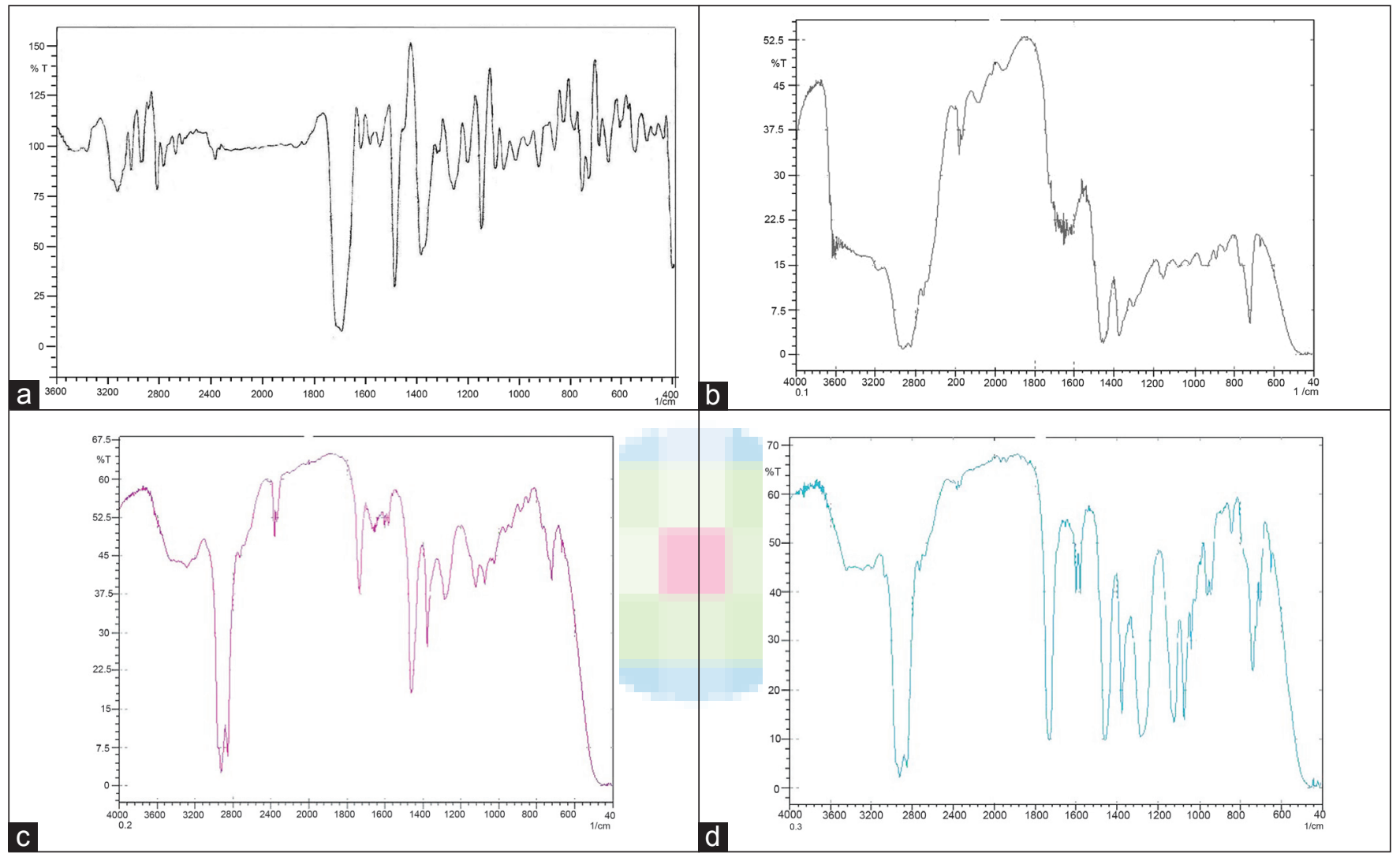

Figure 3: a) IR spectra of domperidone (b) IR spectra of EC:PVP formulation (c) IR spectra of PVA:PVP formulation (d) IR spectra of HPMC: Sodium CMC formulation

Table 7: $\mathbf{R}^{2}$ values of all the prepared transdermal patches

\begin{tabular}{lcccccc}
\hline Code & F1 & F2 & F3 & F4 & F5 & F6 \\
\hline Zero order & 0.9105 & 0.7957 & 0.8497 & 0.8443 & 0.8512 & 0.7440 \\
First order & 0.8552 & 0.7649 & 0.8244 & 0.8397 & 0.8398 & 0.7163 \\
Higuchi model & 0.9967 & 0.9701 & 0.9850 & 0.9906 & 0.9965 & 0.9595 \\
\hline
\end{tabular}

Table 8: Stability study of transdermal patches at various temperature and humidity

\begin{tabular}{|c|c|c|c|c|c|c|c|}
\hline \multirow[t]{2}{*}{ Code } & \multirow{2}{*}{$\begin{array}{c}\text { Initial } \\
\% \text { drug } \\
\text { content }\end{array}$} & \multicolumn{3}{|c|}{$25 \pm 2^{\circ} \mathrm{C}(60 \pm 5 \% R H)$} & \multicolumn{3}{|c|}{$40 \pm 2^{\circ} \mathrm{C}(75 \pm 5 \% \mathrm{RH})$} \\
\hline & & 15 days & 30 days & 60 days & 15 days & 30 days & 60 days \\
\hline $\mathrm{F} 1$ & 94.5 & 94.2 & 94.3 & 93.9 & 94.2 & 94.3 & 92.1 \\
\hline $\mathrm{F} 2$ & 92.5 & 92.1 & 92.3 & 90.8 & 92.3 & 92.1 & 91.9 \\
\hline F3 & 91.57 & 91.28 & 92.08 & 90.36 & 90.35 & 92.09 & 90.54 \\
\hline F4 & 98.3 & 97.21 & 98.06 & 97.24 & 98.2 & 97.07 & 96.35 \\
\hline F5 & 93.25 & 93.15 & 93.06 & 92.25 & 93.12 & 93.09 & 91.52 \\
\hline F6 & 96.06 & 96.12 & 96.09 & 95.36 & 96.21 & 95.24 & 95.11 \\
\hline
\end{tabular}


patches were found to be physically and chemically stable during the study period (60 days).

Results of skin irritancy study revealed that neither blank patch nor patch containing domperidone causes any noticeable sign of erythema or edema on rabbit skin throughout the period of $48 \mathrm{~h}$. Hence, the patches were found to be compatible with the skin.

\section{CONCLUSION}

Di-butylphthalate was used as plasticizer at a concentration of $0.01 \%$ v/v for F4 and F5 and $0.1 \%$ v/v for F1, F2, F5, and F6 which exhibited good flexibility, tensile strength, hardness and handling property. DMF was included as permeation enhancer at a concentration of $0.04 \% \mathrm{v} / \mathrm{v}$, which enhanced the drug release through cellophane membrane and rabbit for in vivo study. Based on the physicochemical parameters and in vitro release studies, formulation F5 and F6 were considered as the best formulations which exhibited the drug release of $36.83 \%$ and $39.38 \%$ through cellophane membrane and $32.56 \%$ through rabbit by in vivo study at the end of $24 \mathrm{~h}$, respectively. While comparing the rate of permeation of drug through the cellophane membrane and rabbit in vivo study, the cellophane membrane has shown the best permeation. Based on the encouraging results, the domperidone transdermal patch can be used as controlled drug delivery system in the treatment of nausea and vomiting, where the drug is made available for an extended period of time, so frequency of administration can be minimized. Though the efforts were made for the development of domperidone transdermal patch, long term pharmacokinetic and pharmacodynamic studies are needed to undertake the establishment of the usefulness of these patches.

\section{ACKNOWLEDGMENT}

I especially thank Torrent Pharmaceutical Ltd., Ahmedabad for providing the drug sample. I also would like to thank Mr. Prabhakar Prabhu, Asst. Professor, N.G.S.M. Institute of Pharmaceutical Sciences, Mangalore (Karnataka) for guiding the research work.

\section{REFERENCES}

1. Tyle P. Drug delivery devices. Fundamentals and applications.
Chapter 13, New York: Marcel Dekker, Inc; 1998. p. 385-417.

2. Basak SC, Vellayan K. Transdermal drug delivery systems. East Pharm 1999;40:63-7.

3. Chein YW. Novel drug delivery systems. Vol. $50,2^{\text {nd }}$ ed. New York: Marcel Dekker Inc.; 1992. p. 301-75.

4. Misra AN. Transdermal drug delivery In: Jain NK, editors. Controlled and novel drug delivery. New Delhi: CBS Publishers and Distributors; 2004. p. 101-17.

5. Finin BC, Morgan TM. Transdermal permeation enhancers: Application, limitations and potentials. Int $\mathrm{J}$ Pharm Sci 1999;88:955- 957.

6. Shinde AJ, Shinde AL, More HN. Design and evaluation of transdermal drug delivery system of gliclazide. Asian J Pharm 2010;4:121-9.

7. Shah SS, Rahul J, Prabhakar P. Formulation and evaluation of transdermal patches of papaverine hydrochloride. Asian J Pharm 2010;4:79-86.

8. Sankar V, Johnson DB, Sivanand V, Ravichandran V, Raghuram $\mathrm{S}$. Design and evaluation of nifedipine transdermal patches. Indian J Pharm Sci 2003;65:510-5.

9. Manvi FV, Dandagi PM, Gadad AP, Mastiholimath VS, Jagadesh T. Formulation of a transdermal drug delivery system of ketotifen fumarate. Indian J pharm 2003;65:239-43.

10. Shah SS, Joshi R, Praphu P. Formulation and evaluation of transdermal patches of papaverine hydrochloride. Asian $\mathrm{J}$ Pharm 2010;4:79-86.

11. Gattani SG, Gaud RS, Chaturvedi SC. Formulation and evaluation of transdermal films of ondansetron hydrochloride. Indian Drugs 2006;43:245-51.

12. Lewis S, Pandey S, Udupa N. Design and Evaluation of matrix type and membrane controlled transdermal delivery systems of nicotine suitable for use in smoking cessation. Indian J Pharm Sci 2006;68:179-84.

13. Chudasama A, Patel V, Nivasarkar M, Vasu K, Shishoo C Investigation of microemulsion system for transdermal delivery of itraconazole. J Adv Pharm Technol Res 2011;2:30-7.

14. Das MK, Bhattacharya A, Ghosal SK. Transdermal Delivery of Trazadonena Hydrochloride from Acrylic films prepared from aqueous latex. Indian J Pharm Sci 2006;68:41-6.

15. Jibry N, Murdan S. In vivo investigation, in mice and in man, in to the irritation potential of novel amphiphilogels being studied as transdermal drug carriers. Eur J Pharm Biopharm 2004;58:107-19.

16. Aqil M, Zafar S, Ali A, Ahmad S. Transdermal drug delivery of labetolol hydrochloride: System development, in vitro, ex vivo and in vivo characterization. Curr Drug Deliv 2005;2:125-31.

How to cite this article: Prabhu P, Shah S, Gundad S. Formulation development and investigation of domperidone transdermal patches. Int J Pharma Investig 2011;1:240-6.

Source of Support: Torrent Pharmaceutical Ltd., Ahmedabad. Conflict of Interest: None declared.

\section{Staying in touch with the journal}

1) Table of Contents (TOC) email alert

Receive an email alert containing the TOC when a new complete issue of the journal is made available online. To register for TOC alerts go to www.jpionline.org/signup.asp.

\section{2) RSS feeds}

Really Simple Syndication (RSS) helps you to get alerts on new publication right on your desktop without going to the journal's website. You need a software (e.g. RSSReader, Feed Demon, FeedReader, My Yahoo!, NewsGator and NewzCrawler) to get advantage of this tool. RSS feeds can also be read through FireFox or Microsoft Outlook 2007. Once any of these small (and mostly free) software is installed, add www.jpionline.org/rssfeed.asp as one of the feeds. 